\title{
THE RELATION OF STRENGTH OF STIMULUS TO RATE OF LEARNING IN THE CHICK
}

\author{
By LAWRENCE W. COLE, (The UnTerstry of Colorado) \\ From the Harvard Psychological Laboratory \\ ONE FIGURE
}

The experiments described in this paper were undertaken in order to learn under what strength of stimulus chicks most rapidly learn to make, respectively, an easy, a medium, and a difficult discrimination. Yerkes and Dodson discovered, in the case of the dancing mouse, that when "discrimination is extremely difficult the rapidity of learning at first rapidly increases as the strength of the stimulus is increased from the threshold, but, beyond an intensity of stimulation which is soon reached, it begins to decrease," while when "discrimination is easy, the rapidity of learning increases as the strength of the electrical stimulus is increased from the threshold of stimulation to the point of harmful intensity." In other words, there appears to be an optimal strength of stimulus for each degree of difficulty of discrimination and the intensity of this optimal stimulus is less the more difficult the discrimination which is to be made.

It was proposed, then, to test the chick's rate of learning io discriminate by a method similar to that which had been employed with the dancing mouse. The work was done in the Harvard Psychological Laboratory and my thanks are due to Professor R. M. Yerkes for the plan of the investigation. The method of measuring the units of electrical stimulation and of calibrating the inductorium for that purpose is that of Doctor E. G. Martin of the Harvard Medical School. ${ }^{2}$ The values of stimuli are relative, not absolute. Since the publication of the paper of Yerkes and Dodson, referred to above, Doctor Martin has discovered that certain corrections should be made which were not made for the original calibration published in the Yerkes and Dodson paper. All of the values of stimuli used in

\footnotetext{
1 Yerkes, Robert M. and Dodson, John D. The relation of strength of stimulus to rapidity of habit formation. Jour. of Comp. Neur. and Psych., 1908, vol. 18, pp. $459-482$.

${ }^{2}$ Martin, E. G. A quantitative study of faradic stimulation. I. The variable factors involved. Amer. Jour. of Physiol., vol. 22, pp. 61-74. II. The calibration of the inductorium for break shocks. Ibid., pp. 116-132.
} 
their investigation, as given in their paper, are relative as are those of the present paper.

The chicks. In the experiments sixty-eight barred Plymouth Rock chicks were used, six in preliminary tests and sixty-two under the established conditions of the experiments. The eggs from which the chicks were hatched were all obtained from a single poultry breeder and were guaranteed to be of pure stock. It was necessary, however, to purchase six young chicks of another breeder, but these also were warranted to be pure barred Plymouth Rock chicks and they were kept until it was certain that they presented no marks of difference from the rest of our chicks. Six chicks were used in every series of tests except three. Under the medium condition of discrimination. with the weakest stimulus which was employed four chicks were used, while in each of two other groups a chick became sick during the progress of the experiments.

When the chicks were eight days old they were given two days of preliminary training (twenty trials) in order that they might learn the way through the experiment box. This was followed by twenty trials in order to ascertain whether the chick had a preference for either the lighter or the darker screen, thus the training series began in every case on the twelfth day after hatching. The training continued until the chick had made twenty consecutive choices of the darker screen. Thus the order of tests, for each chick, was (I) preliminary series, (2) preference series, (3) training series.

Apparatus. Figure I represents in its essential details the apparatus which was used in the investigation. The electrical connections are omitted and the electric key, $\mathrm{K}$, was somewhat further to the right than appears in the figure. For convenience of description we may consider the apparatus as composed of three divisions or boxes. (I) The hover box, $\mathrm{O}$; (2) the illumination box which contains the electric lamps and has for its nearer end the two opal glass screens $N_{3}$ and $N_{3}$, and their frame or holder; (3) the experiment box which has the screens and holder for its remote end and consists of two compartments, $\mathrm{A}$ and $\mathrm{C}$.

The hover box, $\mathrm{O}$, had dimensions of roo $\times 27.5 \times 2 \mathrm{rm} .^{3}$ Its floor was covered with sand and midway of its length was

${ }^{8}$ All dimensions are given in the order length, width, and depth, and are inside measurements. 


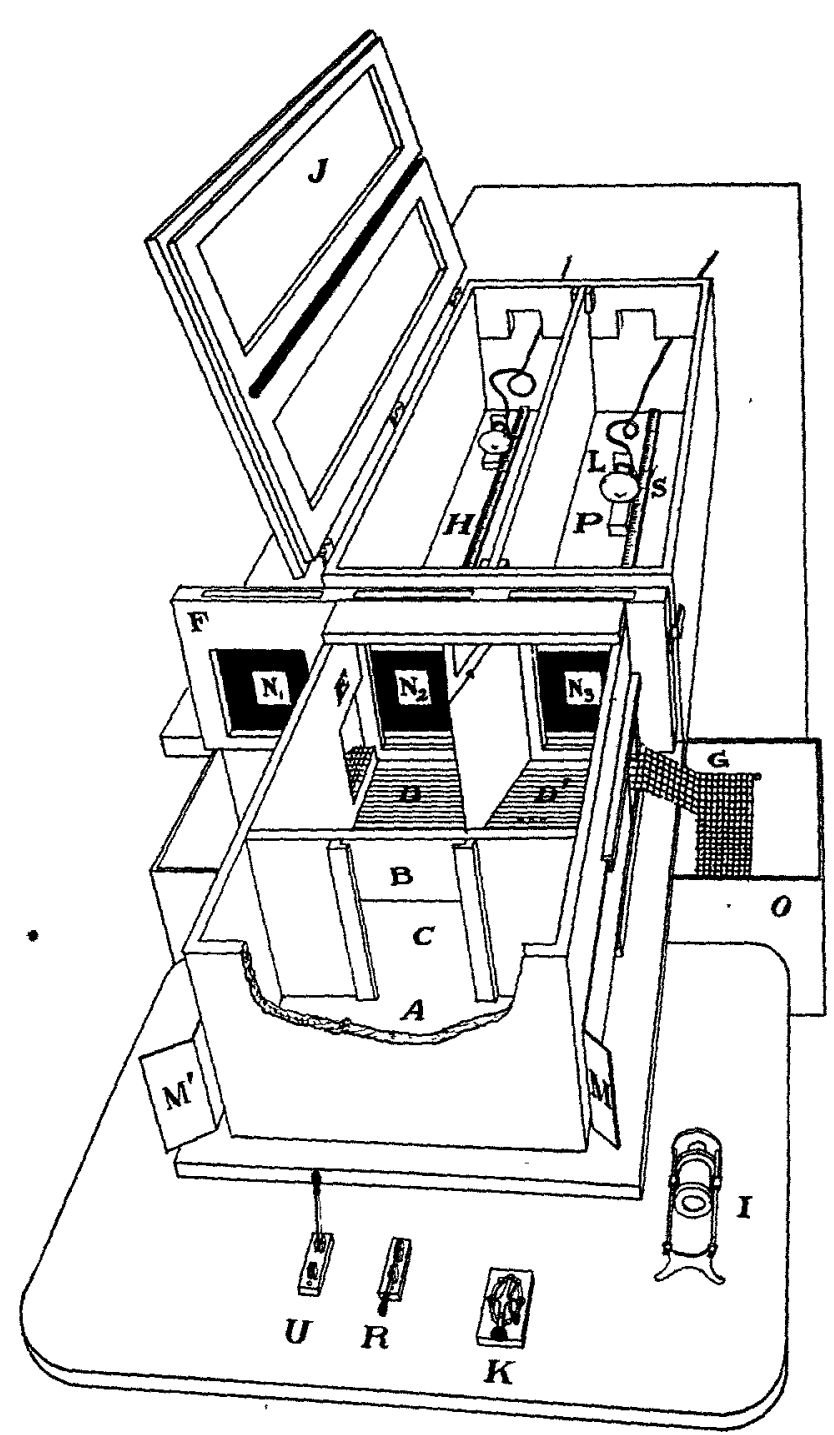

113

FIGURE 1-The figure is symmetrical, hence the letters $G, E, L$, and $S$ must be understood to designate both the parts which they respectively mark and these parts on the opposite side of the figure.

. 1. Hover box O. bover box; $G$, incling from the doors, $\mathrm{E}$, of the experiment wooden platforms) of mox

box to the hover box. $\mathrm{H}$, left compartment; $\mathrm{P}$, right compartment; $\mathrm{L}$, 2. $\mathrm{S}$, metric scales.

amps; $\mathrm{S}$, meriment box: A, compartment in which chick was placed; $\mathrm{C}$, com3. Din which it made cholce of screens; $B$, gateway between $A$ and $C$. partment $D^{\prime}$, electric passageways; $\mathrm{N}_{2}$ and $\mathrm{N}_{3}$, illuminated glass screens to be discriminated; $E$, openings to platforms at the sides of the $U$ and $R$, electre $M$ and $M^{\prime}$, cardboard shutters for closing $\vec{p}$, respectively; $K$, stimulus key; $I$, keys for extinguishing lamps in $H$ and $P$, respect inductorium. 
an electric, I 6 c.p., lamp (not shown in the figure) in a small box fitted with milk-glass windows. This lamp afforded light and warmth to the young chick during the intervals when it was in the hover box, and gave to a small area in the middle of this box approximately the temperature of the brooder in which the chicks were reared. The result of this was that chicks placed in $O$ hovered near this lamp and thus rarely made, at either end of the box, any sounds which might influence the chick in the experiment box in its choice of a passageway back to $O$.

The inclined planes, $\mathrm{G}$, of box $\mathrm{O}$ were replaced, early in the experiment, by two small platforms at the level of the floor of the experiment box. From thèse platforms the chicks hopped down directly to the floor of box $\mathrm{O}$. This change was made because it was found that while chicks very readily walk up an inclined plane it is very difficult and apparently unnatural for them to walk down such planes. This difficulty becomes evident if one tries to imagine a man descending a steep incline with his body leaning far forward. The inclined planes, therefore, to the inconvenience of the experimenter, served rather to toll the chicks in box $\mathrm{O}$ upward toward the small doors of the experiment box than to give a means of descent for the chick which was escaping from the latter box. The platforms obviated this difficulty.

The lllumination box, $107.8 \times 40.2 \times 23.2 \mathrm{~cm}$., was divided lengthwise into two compartments by a light tight partition. The inside dimensions of each compartment were $107.8 \times 19.3 \times$ $23.2 \mathrm{~cm}$. Each of these compartments held an incandescent lamp of the oval reflector type with frosted globe. These lamps were mounted on slides so that they could be moved easily along the millimeter scales, $\mathrm{S}$. They were rated as of 50 c.p: When photometered at the close of the experiments the lamp in the right compartment had an intensity of 42.6 c.p., the one at the left $4 \mathrm{I} .2$ c.p. By moving the lamps along their millimeter scales they could be changed in position from $8.5 \mathrm{~cm}$. to 103 $\mathrm{cm}$. behind the opal glass screens, $\mathrm{N}_{2}$ and $\mathrm{N}_{3}$, so that a wide range of intensities of illumination was available.

As already stated, three different conditions of discrimination were used. For the condition termed "easy" one screen was illuminated by a lamp $33.5 \mathrm{~cm}$. distant, the other screen was not illuminated. For "medium" discrimination one lamp was 
at $23.5 \mathrm{~cm}$, the other at $98.5 \mathrm{~cm}$., and for difficult discrimination the lamps were placed respectively at $23.5 \mathrm{~cm}$. and $53.5 \mathrm{~cm}$. from the screens.

The experiment box was, as shown in the figure, somewhat narrower than the illumination box. It was divided into two compartments, A, $30 \times 16.7 \times 21.3 \mathrm{~cm}$., and C, 46 (from partition $B$ to the glass screens $N_{2}$ and $N_{3}$ ), $\times 30 \times 21.3 \mathrm{~cm}$. A damp pad of felt was placed on the floor of compartment A during the experiments and a similar pad in compartment $C$ extended from the partition, $B$, to within $2 \mathrm{~cm}$. of the electric wires. These pads were used to moisten the feet of the chicks, for when dry the horny epidermis served to protect the animals perfectly from the electric stimulus. The opening, shown in the partition, B, between the two compartments was closed by a mesh wire door which could be opened by lifting it vertically. That half of the floor of compartment $C$. which was nearest the screens was wound with seventeen turns of phosphor bronze wire of No. 20 A.S. gauge. The distance between the successive wires was I cm. This wire was in circuit with the secondary coil of the inductorium, I, and the circuit could be closed by means of the electric key, $\mathrm{K}$. A V-shaped partition divided the wired portion of this compartment into two passageways, $D$ and $D^{\prime}$. From these passageways two openings (of which one, marked $\mathrm{E}$, is shown) gave means of egress for the chick to the platforms (see p. II 3 ) and thence to the hover box, $\dot{O}$. They were closed by the cardboard shutters $M$ and $M^{\prime}$.

The two opal flashed glass screens, $\mathrm{N}_{2}$ and $\mathrm{N}_{3},\left(\mathrm{~N}_{1}\right.$ was not used in the experiments) were each $\mathrm{I} 2 \mathrm{~cm}$. square. As already stated, the lamps were placed at different distances behind the two screens so that the latter differed from each other in brightness. Their relative brightnesses when photometered were roughly as follows:

For "easy" discrimination........... $0^{4}: 89$.

For medium discrimination.... . . . . . . . I $\quad$ I $3 \cdot 7$.

For difficult discrimination ......... I : $5 . \mathbf{I}$.

While one screen was not illuminated under the condition of easy discrimination it had a surface of rather high reflecting power and, since the experiments were made in diffused day-

4 This screen was not illuminated. The zero is meant to indicate nothing more than that fact. 
light, its value as perceived by the human eye was not darkness. This factor of reflected light was present throughout the experiments and made the difference in brightness of the two screens, as judged by the experimenter, much less than that indicated by the above ratio. Subjectively estimated the brightnesses of the two screens would stand, respectively, in the ratios I : 20 for easy discrimination, $I: 4$ for medium, and $I: 2$ for difficult.

A current of 2.I amperes was supplied to the primary coil of the inductorium. The interruptions were $44 \pm 5$ per second. The positions of the secondary coil and the corresponding number of units of stimulation appear in table $\mathrm{r}^{\mathrm{s}}$

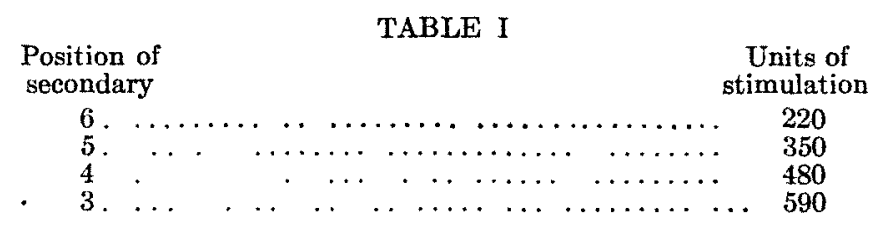

Method of the experiments. As a result of the experiments with the first group of chicks, Nos. I-6 inclusive, it was found necessary to give all subsequent groups twenty trials in the experiment box in order that they might learn both ways of escape from it. The chick was first placed in compartment A of this box. The door in the partition was opened and it passed into compartment $C$. By drawing back the cardboard shutter $\mathrm{M}^{\prime}$ the small door, $\mathrm{E}$, was opened through which the chick escaped to the hover box. In the next trial it escaped at the right and so on until the preliminary series had been completed.

There was no difference of brightness between the two screens during the preliminary tests. During the first five of such tests under the condition of easy discrimination there was no light behind either screen, during the second five trials both lamps were at $33.5 \mathrm{~cm}$. and so on. During the first five tests of medium discrimination both lamps were at $98.5 \mathrm{~cm}$., during the second five at $23.5 \mathrm{~cm}$., and the distances $53.5 \mathrm{~cm}$. and $23.5 \mathrm{~cm}$. were similarly used in the preliminary tests of the difficult discrimination.

\footnotetext{
For the calibration of the inductorium used in these experiments see the paper by Yerkes and Dodson, p. 467.
} 
The experiments with the first group indicated also that chicks without preliminary training showed a very marked tendency to choose the more brightly illuminated screen. I therefore trained the chicks to escape to the hover box by choosing the darker screen. This was done also in order to make the results of my experiments more nearly comparable with those of Yerkes and Dodson, who trained their mice to select the

TABLE II

Positions of Darker Screen for Two Preference Series and Twentyfive Training Series

Subject..... . . Date. ........ Experiment............

\begin{tabular}{|c|c|c|c|c|c|c|c|c|c|c|c|c|c|}
\hline \multirow{2}{*}{ Series } & \multicolumn{12}{|c|}{ Tests } & \multirow{2}{*}{ Remarks } \\
\hline & 1 & 2 & 3 & 4 & 5 & 6 & 7 & $8^{-}$ & 9 & 10 & $\mathbf{R}$ & $\mathrm{W}$ & \\
\hline $\begin{array}{l}\mathrm{A} \\
\mathrm{B}\end{array}$ & $\begin{array}{l}\mathrm{l} \\
\mathrm{r}\end{array}$ & l & $\begin{array}{l}\mathrm{I} \\
\mathrm{r}\end{array}$ & $\underset{1}{\mathbf{r}}$ & $\begin{array}{l}\text { l } \\
\text { r. }\end{array}$ & $\begin{array}{l}\mathrm{r} \\
\mathrm{l}\end{array}$ & $\begin{array}{l}1 \\
r\end{array}$ & $\underset{l}{\mathbf{r}}$ & $\begin{array}{l}1 \\
r\end{array}$ & $\begin{array}{l}r \\
1\end{array}$ & & & \\
\hline $\begin{array}{r}1 \\
: \quad 2 \\
3 \\
4 \\
5 \\
5\end{array}$ & $\begin{array}{l}r \\
l \\
r \\
1 \\
r\end{array}$ & $\begin{array}{l}1 \\
1 \\
r \\
1 \\
1\end{array}$ & $\begin{array}{l}\mathrm{r} \\
\mathrm{r} \\
\mathrm{l} \\
\mathrm{I} \\
\mathrm{r}\end{array}$ & $\begin{array}{l}l \\
r \\
r \\
r \\
1\end{array}$ & $\begin{array}{l}r \\
1 \\
1 \\
r \\
r\end{array}$ & $\begin{array}{l}1 \\
\mathrm{r} \\
1 \\
\mathrm{r} \\
1\end{array}$ & $\begin{array}{l}r \\
l \\
r \\
l \\
r\end{array}$ & $\begin{array}{l}1 \\
1 \\
1 \\
r \\
1\end{array}$ & $\begin{array}{l}\mathbf{r} \\
\mathbf{r} \\
\mathbf{r} \\
\mathbf{r} \\
\mathbf{r}\end{array}$ & $\begin{array}{l}1 \\
r \\
1 \\
1 \\
1\end{array}$ & & & \\
\hline $\begin{array}{r}6 \\
7 \\
8 \\
9 \\
10\end{array}$ & $\begin{array}{l}1 \\
r \\
r \\
r \\
1\end{array}$ & $\begin{array}{l}1 \\
1 \\
r \\
r \\
1\end{array}$ & $\begin{array}{l}r \\
1 \\
1 \\
r \\
l\end{array}$ & $\begin{array}{l}1 \\
1 \\
1 \\
1 \\
1\end{array}$ & $\begin{array}{l}r \\
r \\
r \\
l \\
r\end{array}$ & $\begin{array}{l}\mathrm{r} \\
\mathrm{r} \\
\mathrm{1} \\
\mathrm{r}\end{array}$ & $\begin{array}{l}1 \\
r \\
r \\
r \\
r\end{array}$ & $\begin{array}{l}r \\
1 \\
1 \\
1 \\
r\end{array}$ & $\begin{array}{l}1 \\
r \\
r \\
r \\
1\end{array}$ & $\begin{array}{l}r \\
1 \\
1 \\
1 \\
r\end{array}$ & & & \\
\hline $\begin{array}{l}11 \\
12 \\
13 \\
14 \\
15\end{array}$ & $\begin{array}{l}r \\
r \\
r \\
r \\
r\end{array}$ & $\begin{array}{l}1 \\
1 \\
1 \\
1 \\
1\end{array}$ & $\begin{array}{l}r \\
r \\
r \\
l \\
r\end{array}$ & $\begin{array}{l}r \\
l \\
\text { l } \\
\text { r } \\
r\end{array}$ & $\begin{array}{l}r \\
r \\
l \\
r \\
r\end{array}$ & $\begin{array}{l}1 \\
r \\
1 \\
r \\
\text { I }\end{array}$ & $\begin{array}{l}1 \\
1 \\
r \\
r \\
1\end{array}$ & $\begin{array}{l}1 \\
1 \\
r \\
r \\
1\end{array}$ & $\begin{array}{l}r \\
r \\
r \\
I \\
r\end{array}$ & $\begin{array}{l}1 \\
1 \\
1 \\
r \\
l\end{array}$ & & & \\
\hline $\begin{array}{l}16 \\
17 \\
18 \\
19 \\
20\end{array}$ & $\begin{array}{l}1 \\
r \\
1 \\
r \\
1\end{array}$ & $\begin{array}{l}r \\
r \\
r \\
l \\
l\end{array}$ & $\begin{array}{l}1 \\
r \\
l \\
r \\
l\end{array}$ & $\begin{array}{l}\mathbf{l} \\
\mathbf{r} \\
\mathbf{r} \\
\mathrm{l} \\
\mathrm{r}\end{array}$ & $\begin{array}{l}l \\
1 \\
r \\
r \\
l\end{array}$ & $\begin{array}{l}\mathbf{r} \\
\mathbf{1} \\
1 \\
\mathrm{l} \\
\mathrm{r}\end{array}$ & $\begin{array}{l}r \\
l \\
1 \\
r \\
1\end{array}$ & $\begin{array}{l}r \\
1 \\
r \\
1 \\
r\end{array}$ & $\begin{array}{l}1 \\
r \\
1 \\
r \\
r\end{array}$ & $\begin{array}{l}r \\
1 \\
r \\
1 \\
r\end{array}$ & $\cdot$ & & \\
\hline $\begin{array}{l}21 \\
22 \\
23 \\
24 \\
25\end{array}$ & $\begin{array}{l}r \\
1 \\
r \\
1 \\
r\end{array}$ & $\begin{array}{l}\text { l } \\
1 \\
1 \\
r \\
r\end{array}$ & $\begin{array}{l}1 \\
r \\
1 \\
1 \\
r\end{array}$ & $\begin{array}{l}\mathbf{r} \\
r \\
1 \\
1 \\
r\end{array}$ & $\begin{array}{l}r \\
1 \\
1 \\
1 \\
1\end{array}$ & $\begin{array}{l}1 \\
1 \\
\mathrm{r} \\
\mathrm{r} \\
1\end{array}$ & $\begin{array}{l}1 \\
\mathrm{r} \\
\mathrm{r} \\
\mathrm{r} \\
\mathrm{l}\end{array}$ & $\begin{array}{l}\mathbf{r} \\
\mathrm{r} \\
\mathbf{r} \\
\mathbf{r} \\
\mathbf{l}\end{array}$ & $\begin{array}{l}r \\
j \\
r \\
r\end{array}$ & $\begin{array}{l}1 \\
r \\
1 \\
r \\
1\end{array}$ & & & \\
\hline
\end{tabular}


white box, since, in the preference tests, the dancers selected the black one in more than one-half the trials. ${ }^{\circ}$

As described above (p. 112), the preliminary series were followed by two series of ten trials each, called "preference series," and designated in Table II by the letters A and B. On the day following the completion of the "preference series," the training series was begun and they were continued until the chick had made twenty consecutive choices of the darker screen. The order of change of illumination of the two screens appears in table II. The letter 1 indicates that the screen at the left was the darker one, the letter $r$, that the one at the right was the darker.

Since the preference series were preceded by the twenty preliminary trials, in which the chick escaped from the experiment box by going alternately through the right and left passageways, the preference, so-called, was interfered with by the partially formed habit. Untrained chicks chose the brighter screen uniformly.

During the training series, if a chick chose the lighter passageway, it received an electric shock, whereupon it usually retreated from the wires, the door of the darker passageway was opened and through that it escaped to the hover box. Under this stimulus the chicks quickly learned to choose the darker screen under conditions of easy and medium discrimination. A few chicks were unable, even after many trials, to learn to choose the darker screen under the difficult condition of discrimination.

Results of the Experiments. The results of the experiments appear in table III. This table gives the three conditions of discrimination, easy, medium, and difficult, the relative strengths of the stimuli, the numbers by which the individual chicks were designated, and, opposite each of these, the number of trials which preceded twenty consecutive correct choices, or the number of trials "up to the point at which errors ceased."

In order to spare the reader an annoying repetition of the phrases, "easy, medium, and difficult conditions of discrimination," I shall scmetimes refer to them, respectively, as great, medium, and slight differences of illumination or brightness of the two glass screens.

It is evident from table III that under the condition of easy discrimination the rate of learning is more rapid the stronger

'Yerkes and Dodson, loc. cit., p. 462. 
RAIE OF LEARNING IN THE CHICK

TABLE III

Generai Results of Experiments

\begin{tabular}{|c|c|c|c|}
\hline \multirow{2}{*}{$\begin{array}{l}\text { Units of } \\
\text { stimulation }\end{array}$} & \multicolumn{3}{|c|}{ Condition of discrimination } \\
\hline & $\begin{array}{c}\text { Easy } \\
\text { Lamps at } 33.5 \\
\text { cm. and darkness }\end{array}$ & $\begin{array}{c}\text { Medium } \\
\text { Lamps at } 23.5 \\
\mathrm{~cm} . \text { and } 98.5 \mathrm{~cm}\end{array}$ & $\begin{array}{c}\text { Difficult } \\
\text { Lamps at } 23.5 \\
\text { cm and } 53.5 \mathrm{~cm} .\end{array}$ \\
\hline $\begin{array}{l}220 \\
\text { Secondary } \\
\text { at } \\
6\end{array}$ & & 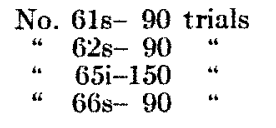 & \\
\hline & & Av. 105 & \\
\hline $\begin{array}{c}350 \\
\text { Secondary } \\
\text { at } \\
5\end{array}$ & $\begin{array}{c}\text { No. } 7-50 \text { trials } \\
8-30 \\
4 \quad 9-20 " \\
. \\
11-60 \\
12-60 " \\
\end{array}$ & 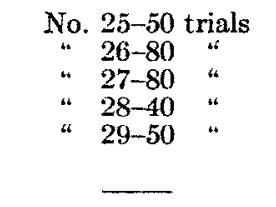 & 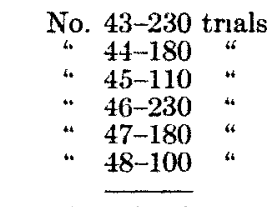 \\
\hline & Av. 44 & Av. 60 & Av. 1716 \\
\hline $\begin{array}{l}480 \\
\text { Secondary } \\
\text { at } \\
4\end{array}$ & 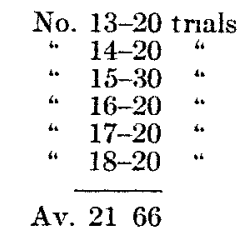 & 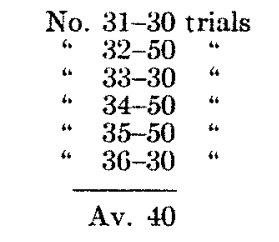 & 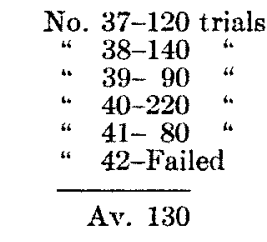 \\
\hline $\begin{array}{l}590 \\
\text { Secondary } \\
\text { at } \\
3\end{array}$ & 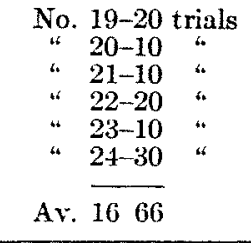 & 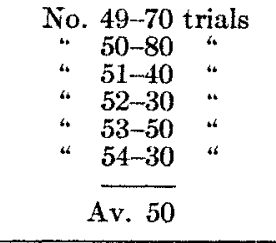 & 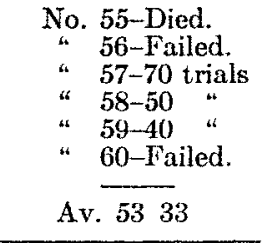 \\
\hline $\begin{array}{l}590 \\
\text { Secondary } \\
\text { at } \\
3\end{array}$ & & 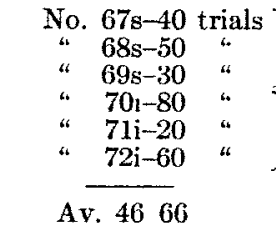 & $\begin{array}{l}\text { Av. } 40 \\
\text { Av. } 5333\end{array}$ \\
\hline
\end{tabular}

the stimulus. With a stimulus of $35^{\circ}$ units an average of 44 trials was required before errors ceased, with 480 units 21.66 
trials, and with 590 units only 16.66 trials. The same relation holds true for medium discrimination and stimuli of $220,35 \circ$ and 480 units, but when a stimulus of 590 units was employed the number of trials required for learning to make the discrimination increased from 40 to 50 . In order to make certain that this increase in the number of learning trials was due only to the strength of the stimulus I repeated the test with a second group of six chicks and the average was practically the same, namely, 46.66 trials. With medium difference of brightness of the two screens, therefore, the optimal stimulus lies nearer the threshold than under the easy condition of discrimination.

The responses of the chicks to the third, or difficult, condition of discrimination are less easy to interpret. With the weakest stimulus used for this condition, 350 units, none of the six chicks failed, with the medium stimulus one failed, and with the strong stimulus two out of five failed. Moreover, the utmost patience was required of the experimenter in order that all should not fail. Each trial also required much more time than in medium and easy discrimination. If, however, we consider only the chicks that learned to make the difficult discrimination the relation stated for easy discrimination appears once more, i. e., the stronger the stimulus the more rapid the learning. It seems clear, therefore, that, with difficult discrimination, the strong stimuli divided the chicks into two groups, (I) those which after a few trials ceased to try to escape and would no longer step on the electric wires, and (2) those which chose with greater and greater caution and, therefore, learned to choose correctly after a small number of trials, each of which consumed much time.

To what shall we ascribe this dual result under the third condition of discrimination? It seemed possible that the chicks were divided into the two groups according to their sensitiveness to the electric stimulus. That is, the more sensitive chicks might learn most rapidly under the influence of a weak stimulus, be slow to learn under the influence of a strong one, and fail completely when under the influence of both a strong stimulus and a difficult condition of discrimination.

In order to answer this question twelve chicks were selected of which number six had a threshold of stimulation of 90 units and the remaining six of $15^{\circ}$ units (relative values). The former 
are designated by the letter $\mathrm{s}$ (sensitive) placed after their numbers in table III, the latter by the letteri (insensitive). Tests were then begun with three sensitive chicks, Nos. 6r, 62, and 66 , and with three insensitive ones, Nos. 63,64 , and 65 , under the medium condition of discrimination and with a weak stimulus. Unfortunately, Nos. $6_{3}$ and 64 died before the tests were completed. No. 65 , however, required I 50 trials for perfect discrimination while each of the sensitive chicks required exactly go trials. The loss of the two insensitive chicks makes a definite conclusion impossible, yet all our work with weak stimuli agrees with the result of the records of these four chicks. It is probable, therefore, that the chicks which were most sensitive to the electric stimulus were the ones which learned most rapidly under the influence of weak stimuli.

Let us turn now to the results of strong stimulation. Should the sensitive chicks be those which failed under the difficult condition of discrimination and strong stimuli they should be slowest to learn with the same stimuli and medium difference of illumination of the two screens, since it was already proved that a strong stimulus increased the learning rate under this condition. Three sensitive chicks (Nos. 67, 68, and 69) and three insensitive ones (Nos. 70, 71 , and 72 ) were, therefore trained under this condition. An examination of their records shows that the sensitive chicks required an average of 40 trials for learning to discriminate between the two screens, while the insensitive ones required 53.33 trials. Evidently, therefore, sensitiveness to the stimulus was not the condition which prevented rapid learning under a strong stimulus.

At the close of these experiments with sensitive and insensitive chicks there seemed to be no explanation for the divergent results under the third, or difficult condition of discrimination. The behavior of the chicks indicated, however, that the pain stimulus impressed the memory of those that failed so deeply and permanently that, after a few experiences of it, they avoided the electric wires completely and would no longer attempt to escape from the experiment box. This observation, based on the chicks' behavior, receives striking confirmation from the records. The records of the successful chicks in the group $37-41$, inclusive, show that in their first fifty trials each chick received an average of 20.4 pain stimuli, while chick 42 , which failed, 
received in the first fifty trials 30 such stimuli. These additional stimuli seemed to inhibit completely the impulse to enter the electric passageways. In the case of chicks 56-60, inclusive, only the average number of pain stimuli received during the first forty trials can be considered as chick 56 would not attempt to escape after the fortieth trial. In the first forty trials chicks 57,58 , and 59 , which succeeded, each received an average of 15.3 pain stimuli. Chicks 56 and 60 received an average of 20.5 such stimuli and failed, while chick 55 , which went to the wrong passageway in nine of the first ten trials, flew from the door of escape with such violence that he was injured in alighting. Those chicks failed, therefore, which made more wrong choices in their early trials and consequently received more pain stimuli than their successful companions. The additional repetitions of the stimulus seem to have stamped in the impression of the pain and to have caused the failures rather than a native difference of brain plasticity as I had supposed on observing the marked difference of behavior between successful and unsuccessful chicks. Here, as elsewhere, repetition seems to be prepotent in determining memory, if these smooth brained and extremely stupid creatures may be said to have memory. The difference between arousing extremely slow and cautious discrimination and inhibiting all efforts to escape lies, I believe, in the added number of pain stimuli given in early trials to the chicks which failed.

Records were kept of the sex of all the chicks used in the experiments but they revealed no correlation between sex and rate of learning. In fact the slow and rapid learners were distributed rather evenly between the two sexes.

Under the conditions of the experiments, it seemed probable that the heavier chicks received stronger electric stimuli than the lighter ones and therefore learned the more rapidly. But the weights of the chicks of several groups were recorded every three days during the period of experimentation without revealing differences between the heavier and the lighter individuals either in behavior or rate of learning. Again, there was no correlation between weight and sensitiveness to the current in the chicks whose threshold of sensitiveness was determined before training them.

I have shown that, for easy discrimination, increase of the inten- 
sity of the stimulus is followed by decrease in learning rate, while, for medium discrimination an optimal intensity of stimulus is found, increase beyond which is followed by slower learning. Thus far my results and those of Yerkes and Dodson in the case of the dancing mouse seem to agree. In the case of the mouse under the difficult condition of discrimination it was found that the optimal stimulus approached much nearer the threshold than with medium difference of illumination between the two boxes. My results with chicks are in conflict with this unless, as has been done, the cases of failure to learn to discriminate are considered. Then it is found that, with the difficult condition of discrimination and the weakest stimulus, none, with the next greater strength of stimulus, one, and with the strongest stimulus two chicks failed. With slight difference of brightness between the two screens the strength of stimulus under whose influence no chicks fail to learn to discriminate is nearer the threshold than the optimal stimulus for the medium condition of discrimination. Perhaps this is as close agreement of the results for mice and for chicks as we should expect to find in animals so unlike. The behavior of the chicks was, however, the reverse of that of the mice. Yerkes writes:" "The behavior of the dancers varied with the strength of the stimulus to which they were subjected. They chose no less quickly in the case of the strong stimulus than in the case of the weak, but they were less careful in the former case and chose with less deliberation and certainty." My chicks, on the other hand, chose quickly with weak stimuli, but only after long delay with strong stimuli. A chick would sometimes require ten or fifteen minutes to make a choice in the latter case. This difference might perhaps be accounted for by the fact that, with the mouse, a moveable cardboard partition was used by which the space in which the animal could move was gradually restricted. Thus a choice of one passageway or the other was finally necessary. This device could not be used satisfactorily with chicks.

The record of one chick, which appeared to be perfectly normal when I began experiments with it, but died before they were completed, deserves notice. Its training series on successive days were as follows:

\footnotetext{
7 Yerkes and Dodson, loc. cit., p. 476.
} 


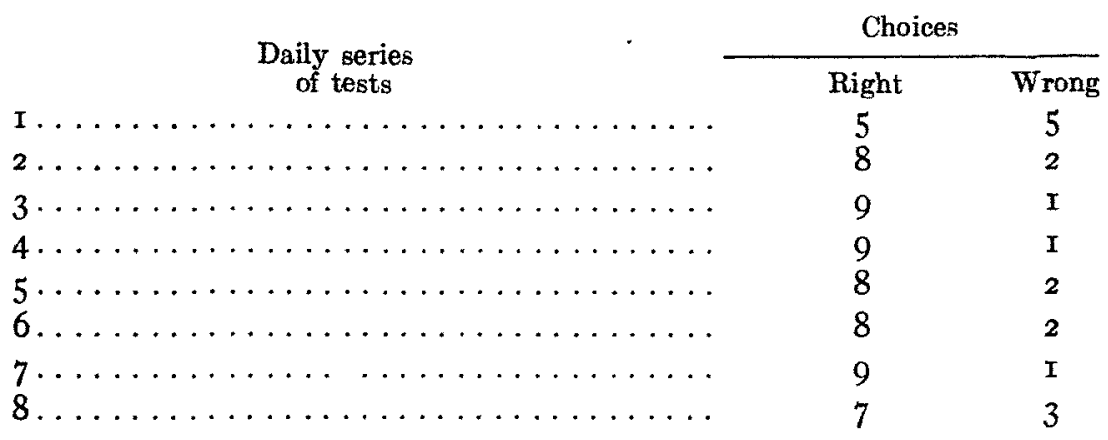

On the ninth day the chick was weak and would not choose either passageway. When I dissected it a large intestinal cyst was found in which there was much food and a fluid secretion. Such a cyst could have formed in a few days. But the important point is that the only sign of ill health in this chick for four days was the decrease in the number of right choices. On the fifth day physical signs of weakness appeared.

In conclusion, it is evident that within the limits of the stimuli which I used, the number of trials required by the chick to learn to choose consecutively the darker of two unequally illuminated screens, when discrimination is easy, decreases with an increase of stimulus. Under medium difficulty of discrimination the above law holds true only for the lower intensities of the stimuli which were used, or, in other words, the optimal stimulus recedes toward the threshold from 590 to 480 units. The above law for the condition of easy discrimination holds true for that of difflcult discrimination if we consider only the records of the chicks which succeed in learning to make the discrimin:ation. If, however, we consider only the chicks which fail, the optimal stimulus recedes once more to a point nearer the threshold. of stimulation than in the case of medium discrimination. In other words, with the difficult condition of discrimination, strong stimulj divide the chicks into two groups, those which succeed in learning to discriminate by reason of more right choices at the beginning of the training series and consequently fewer pain stimuli, and those which fail because of fewer right choices and more pain stimuli in the earlier trials. So far as I determined the sensitiveness of the chicks it may be said that on the average the more sensitive chicks learned more rapidly both for strong and for weak stimuli. 